\title{
CAPTURING KNOWLEDGE IN ORDER TO OPTIMIZE THE CUTTING PROCESS FOR POLYETHYLENE PIPES USING KNOWLEDGE MODELS
}

\author{
ROTARU Ionela Magdalena \\ assistant professor Ph.D., Faculty of Engineering/Department Industrial Engineering and Management., \\ "Lucian Blaga" University, Sibiu, Romania, ionela.rotaru@ulbsibiu.ro
}

\begin{abstract}
Knowledge management is a powerful instrument. Areas where knowledge - based modelling can be applied are different from business, industry, government to education area. Companies engage in efforts to restructure the database held based on knowledge management principles as they recognize in it a guarantee of models characterized by the fact that they consist only from relevant and sustainable knowledge that can bring value to the companies. The proposed paper presents a theoretical model of what it means optimizing polyethylene pipes, thus bringing to attention two important engineering fields, the one of the metal cutting process and gas industry, who meet in order to optimize the butt fusion welding process - the polyethylene cutting part - of the polyethylene pipes. All approach is shaped on the principles of knowledge management. The study was made in collaboration with companies operating in the field.
\end{abstract}

Key words: butt fusion welding process, polyethylene pipes, metal cutting process, process optimization, knowledge management

\section{Introduction}

Due to the advantages that they have - reliability thermoplastic materials, durability, aviability on market in various range of pressures and diameters, easy to work with (easy to join toghether pipes or fittings), light weight, corrosion resistant, flexible, at a good cost they represent a good solution for the water and gas distribution nettworks.

Plastics have steadily replaced clay, copper, asbestoscement, aluminium, iron, and concrete pipes in various applications. Among the plastics employed in pipes, PVC accounts for about $75 \%$ while polyethylene is employed in about $20 \%$ of the plastic pipes applications. Polyethylene (PE) pipes are used extensiveley for the transportation and distribution of natural gas and water, accounting for about $80 \%$ of the new piping installations [1].

The polyethylene pipes can be welded by various methods. This paper will cover the butt fusion welding of the polyethylene pipes.

The object of the research is to design a metodology intended for the optimization of front cut of the pipes. Due to the advantages that knowledge management presents the findings will be captured in the form of a concept map - a powerfull instrument of knowledge management.

The major benefit revealed in this paper consists in the capacity of knowledge models to offer pre-defined solutions for the systems they were designed. [4,5] The complex nature of a design process demands structured knowledge delivery in order to increase the quality of the response and to decrease the reaction period of time "Knowledge is not a picture of reality; it is much more a map of those actions that reality permits. It is a repertoire of concepts, semantic relationships and actions or operations that have proven to be viable for the attainment of our goals” [ 2,3$]$.

\section{Butt fusion welding process of polyethylene pipes}

In order to understand the place of the cutting process in the process of welding of the polyethylene pipes will be presented in the following the technological approach for the butt fusion welding process. The presented technology is designed for an automatic machine tool - Fusion Gator - 
Figure 1and the dimensions that can be welded are from 63 to $630 \mathrm{~mm}$. The technology consists of a single operation that can be broken down into phases:

1. clamp the pipes

2. cutting the frontal part of polyethylene pipes

3. withdrawal tool-holder device

4. nearby pipes

5. intermediate visual inspection

6. spacer tube

7. descent hob

8. heating the pipes end zone to form the burr

9. withdrawal hob

10. pressing pipes

11. loose pipe

12. the final control
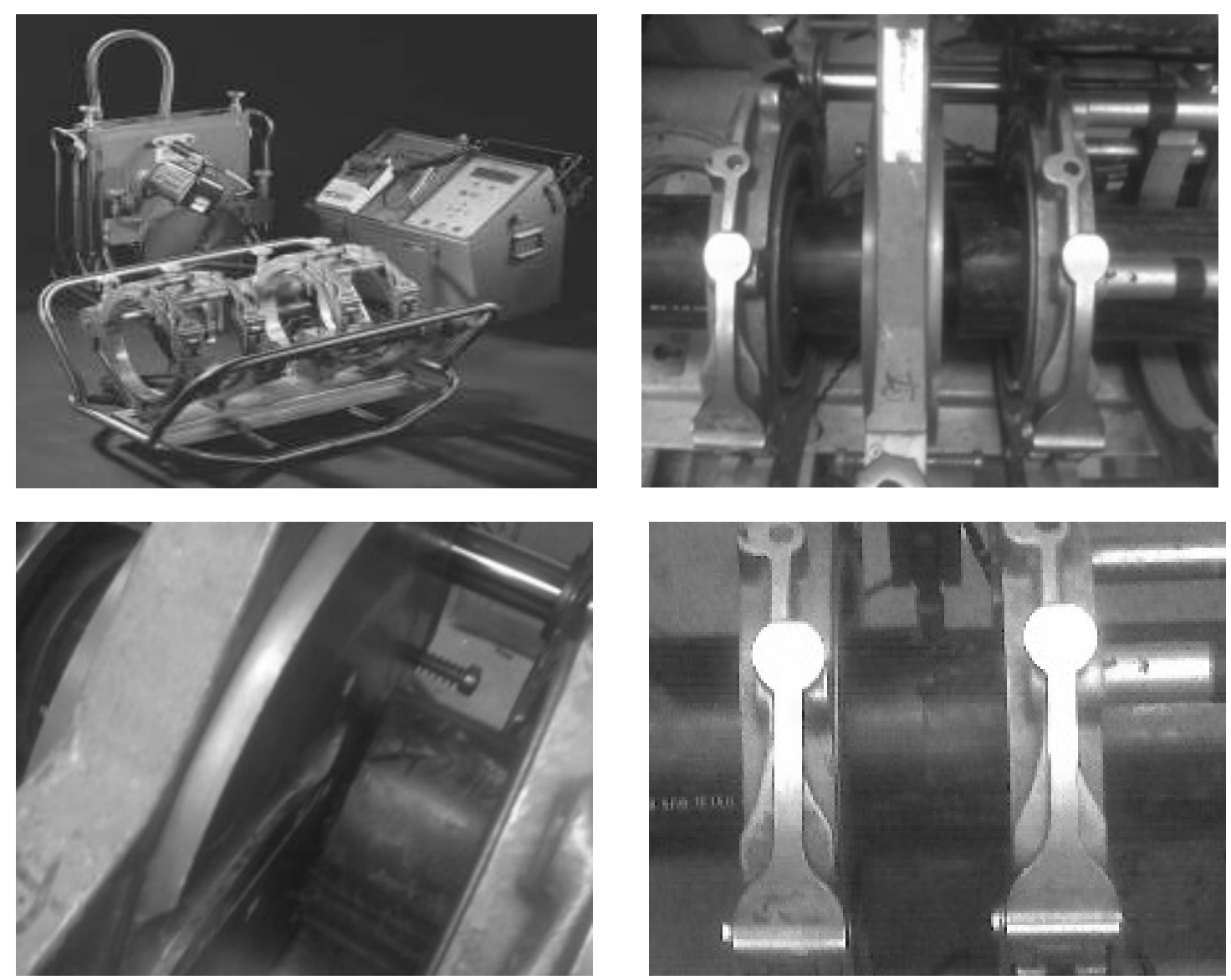

Figure1. Machine tool - Fusion Gator and stages of the technological process

\section{Study on the optimization of the polyethylene cutting pipes process based on knowledge management}

This research was conducted in collaboration with Fusion Romania Company, the preferred provider of polyetylene pipes and fittings in Romania.

The stages that will achieve optimization of the processing technology front for polyethylene tubular pieces are summarized below:

1. defining and identification the scope of the research - the starting point of the research, of particular importance, a correct identification of the given theme It is one of the premises for a successful research;

2. the choice of the appropriate research method - it represents an important stage of the research, with a decisive role; 
3. research planning - consists in four important sections regarding: the proposed targets, a current state of art, preliminary studies and research design;

4. the processing carried out in order to collect necessary data for the optimization technological equipment selection, determining the parameters of the processing regime, sample preparation, practical execution of processing, recording of results;

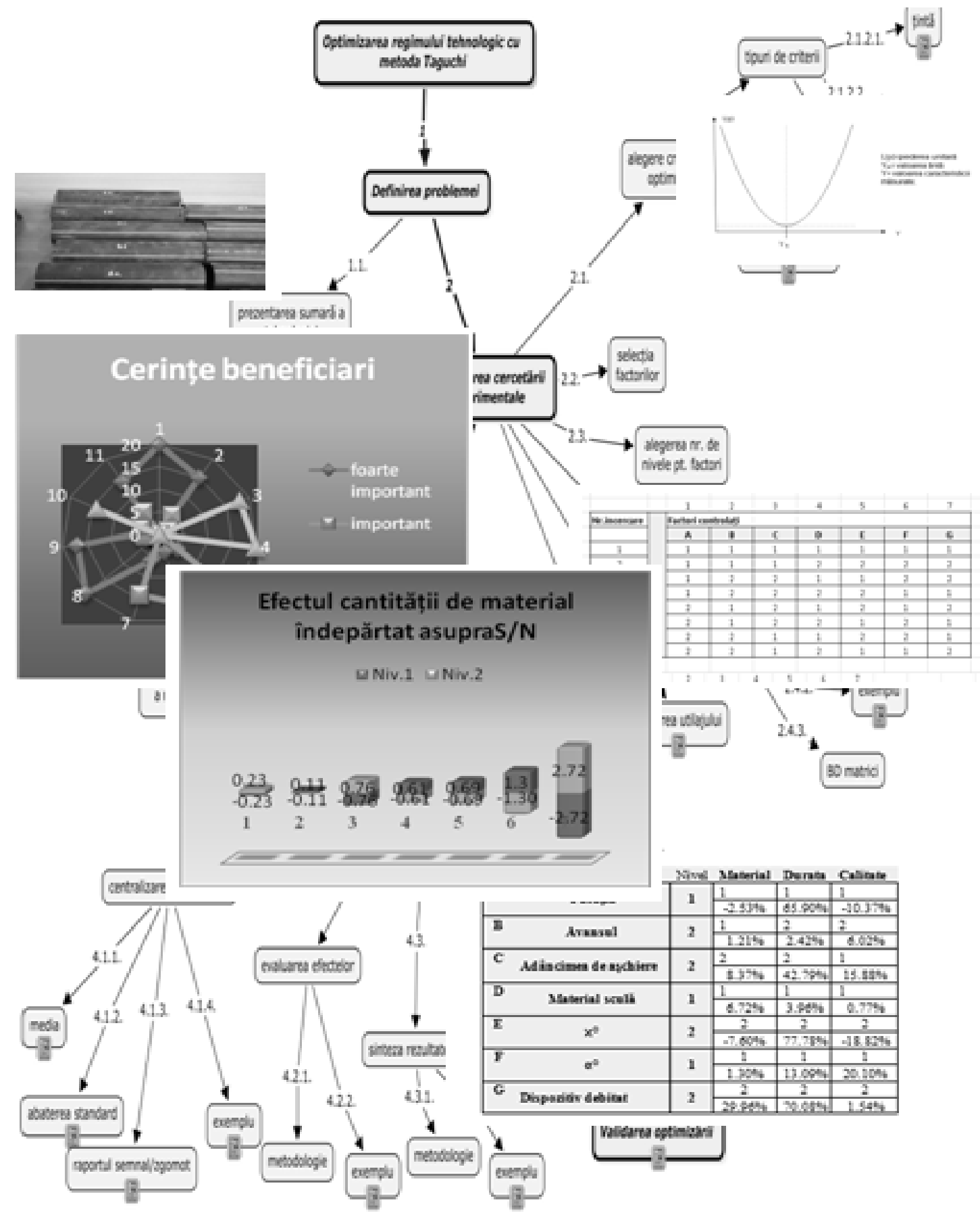

Figura.2. Theoretical knowledge model

5. measurements conducting - processing results will be measured - such as surface quality achieved;

6. processing of results - in this stage the informations are brought in a manner that allows their analysis and interpretation;

7. analysis and interpretation of information - in the end, this complex of activities, returns the result for the conducted research;

8. qualitative validation optimization - it validates the obtined results. 
All the outlined steps have been modeled as a knowledge model. The theoretical model is presented in the Figura.2. Theoretical knowledge model. The instrument for the knowledge representation is a Concept Map because of the benefits the concept map brings: the resulted knowledge is presented accordingly to the type of knowledge which must be submitted (the proposed model contains a number of 21 folders that incorporates questionnaires, graphs, figures, movies, and other supporting documents such as registration forms for recording the results of the research), the knowledge is structured in a way that is underlines the connection between the various concepts presented, the knowledge is stored, can be easy accesed, past experience may be a good base for problem solving, nonexperienced have the advantage of other peoples experiences, being driven in his approach to achieve optimization [4].

Each step is presented in detail. Thus, for example, the first stage contains knowlede related to the topics: summary of technology - is presented in the introduction of the paper, the processed material

- processed material is the polyethylene pipe material and is covered by the European standard EN12201 - 2: 2003., the machine-tool - is a machine automatic welding machine, Fusion Gator - for the range of 63-630 mm diameter, the cutting tool tool-holder and and the tool both presented in figure 3.
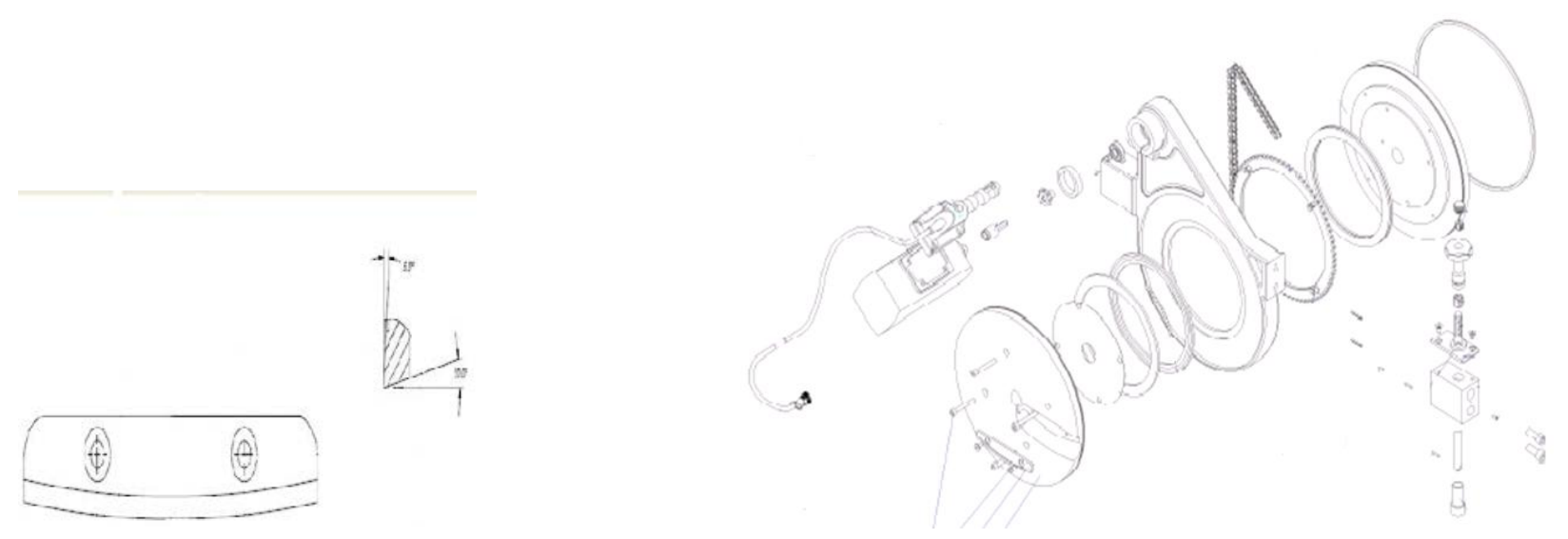

Figure3. Cutting tool and cutting tool holder

\section{Conclusions}

The research presents a theoretical model for process optimization. Such model is useful as basic decision support for process optimization. The model allow the capture and reuse of knowledge in order to achieve the required optimization. The theoretical model can be used as a form of transmission of knowledge given the benefits they shows: the resulted knowledge is presented accordingly to the type of knowledge which must be submitted, the knowledge is structured in a way that is underlines the connection between the various concepts presented, the knowledge is stored, can be easy accesed, past experience represents a base for knowledge improvement and dissemination.

\section{Acknowledgements}

This work was supported by the strategic grant POSDRU/159/1.5/S/133255, Project ID 133255 (2014), co-financed by the European Social Fund within the Sectorial Operational Program Human Resources Development 2007 - 2013.

\section{References}

1. Mruk, S., Pipe, Encyclopedia of PolymerScience and Technology, 2nd, ed., Vol. 11, pp. 226, Willey, New York, (1988).

2. Meyer, Bertolt,Kozo, S., The concept of knowledge in KM: a dimensional model, Journal of knowledge management, Vol. 10,No.6, (2006).

3. Rotaru, Ionela Magdalena, Lobont, Lucian, Radu, V. Knowledge models in Engineering Technology and Manufacturing. A specific example, International conference on Manufacturing Science and education, MSE, Sibiu, (2011).

4. Rotaru, Ionela Magdalena, Knowledge models in Engineering Technology and Manufacturing, International conference on Manufacturing Science and education, MSE, Sibiu, (2011).

Rotaru, Ionela Magdalena, Borza, Sorin, Conception and fabrication in automotive industry using knowledge management principles, The 6th Balkan Region Conference on Engineering and Bussines Education, BRCEE, Sibiu, (2012). 